\title{
Hereditary Breast and Ovarian Cancer Syndrome (BRCA) Gene: Concept, Pathways, Therapeutics, and Future
}

\begin{abstract}
Hereditary breast and ovarian cancers are most commonly caused by mutations in BRCA1 and 2 genes. These are autosomal dominant mutations with high penetrance into subsequent generations. Affected individuals have deficiency in DNA repair mechanisms such as double strand DNA breaks (DSB) and non-homologous end joining (NHEJ). These tumors are peculiar due to early age of onset, typical histology such as triple negative breast cancers and high grade serous ovarian cancers and exquisite sensitivity to platinum analogues. These patients usually have better survival as compared to their wild type counterparts. Incidence of these mutations is rising due to better awareness about them amongst oncologists and patient population. Various genomic assays are available to detect germline and somatic BRCA mutations. Newer therapeutic frontiers like PARP inhibition have opened up due to better understanding of various mutations and their impact on subsequent pathways. Further studies are required to explore possibility of direct BRCA inhibition which may be useful in treatment of other solid organ cancers as well. This review focuses on understanding the pathophysiology of BRCA mutations, various pathways associated with the same, chemosensitivity patterns amongst affected cancer cells, targeted therapeutic opportunities and potential future developments in this field. We collected data from various published electronic records on google and have no conflicts of interest to be declared.
\end{abstract}

Keywords: BRCA syndrome, BRCA protein inhibition, chemosensitivity, DNA repair deficiency, PARP inhibitors

\section{Epidemiology of Hereditary Breast and Ovarian cancer}

Breast and ovarian cancers are major cancers affecting females. Majority of them are sporadic. However, 5\%-10\% of breast cancers $^{[1]}$ and $20 \%$ of ovarian cancers ${ }^{[2]}$ may exhibit hereditary lineage. The most common genetic mutations among familial breast and ovarian cancers happen in BRCA1 and 2 genes. Germline mutations within either of them are found in approximately $5 \%$ of all breast cancer cases. These mutations are autosomal dominant with high penetrance and variance. The lifetime probability of developing breast cancer in individuals with BRCA1 and 2 mutations is $57 \%-65 \%$ and $45 \%-49 \%$, respectively. The probability of developing ovarian cancer in these individuals is $39 \%-40 \%$ and $11 \%-18 \%$, respectively. ${ }^{[3,4]}$ These individuals are also prone to develop cancers of other organs such as prostate, male breast, and pancreas. ${ }^{[5]}$

This is an open access journal, and articles are distributed under the terms of the Creative Commons Attribution-NonCommercial-ShareAlike 4.0 License, which allows others to remix, tweak, and build upon the work non-commercially, as long as appropriate credit is given and the new creations are licensed under the identical terms.

For reprints contact: WKHLRPMedknow_reprints@wolterskluwer.com
A large epidemiological study in germline BRCA-mutated patients (gBRCA1m or gBRCA2m) showed that hormone receptor positivity (ER/PR) was more common in gBRCA $2 \mathrm{~m}$ than gBRCA1m patients $(77 \%$ and $22 \%$, respectively). ${ }^{[6]}$ Interestingly, ER-positive tumors in gBRCAm patients exhibit different histological features than sporadic tumors. They are more likely to be Luminal B type; have higher grade and higher Oncotype Dx scores. Furthermore, the proportion of ER-positive tumors increases with increasing patient age in BRCA1m carriers but decreases with increasing age in BRCA2m carriers. ${ }^{[6]}$ About $70 \%$ of breast cancers among gBRCA1m patients are triple-negative breast cancer $(\mathrm{TNBC})^{[7]}$ and BRCA1 or 2 mutation is thought to be present in nearly $20 \%$ of all TNBCs. ${ }^{[8]}$

The prevalence of somatic BRCA mutations has not been exactly assessed. Few studies have shown 3\%-5\% of all breast cancer cases ${ }^{[9,10]}$ and nearly $7 \%-8 \%$ of all ovarian cancer cases

How to cite this article: Tamhankar A, Tamhankar $T$ Hereditary breast and ovarian cancer syndrome (BRCA) gene: Concept, pathways, therapeutics, and future. Indian J Med Paediatr Oncol 2020;41:9-14.

\section{Anup Tamhankar ${ }^{1}$, Tanuja Tamhankar ${ }^{2}$}

${ }^{1}$ Deartment of Surgical Oncology, Deenanath Mangeshkar Hospital, Pune, Maharashtra, India, ${ }^{2}$ Novo Life Cancer Clinic, Pune, Maharashtra, India

Submitted: 08-Aug-2019 Accepted in Revised Form: 01-Sep-2019

Published: 24-Apr-2020

\section{Address for correspondence:}

Dr. Anup Tamhankar,

Consultant Surgical Oncologist,

Novo Life Cancer Clinic,

Deccan, Pune - 411004 ,

Maharashtra, India.

E-mail: tamhankaranup@gmail. com

Access this article online

Website: www.ijmpo.org

DOI: 10.4103/ijmpo.ijmpo_172_19

Quick Response Code:

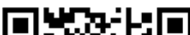


to have somatic BRCA mutations only. ${ }^{[1]}$ Although the prevalence of pure somatic mutations appears to be low, the growing role of PARP inhibitors in breast and ovarian cancers suggests that these patients might be the best possible beneficiaries of assessment for BRCA mutations in both the tissues and blood. ${ }^{[12]}$ Some preliminary work has also suggested that few prostate cancers may have somatic BRCA mutations, and they may benefit by PARP inhibitors. ${ }^{[13]}$

\section{DNA Damage and Role of BRCA in Check Point Activation and DNA Repair in Mammalian Cells}

The cell triggers checkpoints and starts DNA repair process upon exposure to moieties causing DNA damage. If either of these mechanisms fails, it will lead to uncorrected mutations within the genome. This may lead to development of a cancer cell or in extreme scenario, 'self-destructive or suicidal' phenotype. Such cells are also exquisitely sensitive to DNA damaging agents such as ionizing radiation and platin analogs. ${ }^{[14-17]}$

Protein kinases (PKs) ATM, ATR, Chk1, and Chk2 are involved in the regulation of G2M transition checkpoint. After ionizing radiation, ATM phosphorylates serine residues in $\mathrm{C}$ terminal of BRCA1. ${ }^{[18,19]}$ This activates BRCA1 into further cascade. ATM activation also leads to Chk2 activation which phosphorylates, Ser988, in BRCA1. ${ }^{[20]}$ This causes appropriate localization of BRCA1 upon DNA damage. Deficiency of ATM leads to failure of BRCA1 activation which leads to defective DSB repair. Cancers in patients of Ataxia Telangiectasia exhibit quite clinical similarity to BRCA1-deficient patients.

DNA repair in mammalian cells takes place mainly through two processes; homologous recombination (HR) and nonhomologous end joining (NHEJ). NHEJ depends on DNA-dependent PKs which add residues to the broken ends without any direct regard to homology with the sister strand. HR happens through the exchange of information between damaged strand and its normal sister counterpart. While NHEJ is more error prone, HR is more full-proof mechanism of DNA repair and appears to be better conserved among all mammalian and eukaryotic species. BRCA2 appears to be essential for HR only as BRCA2 deficient cells still retain their ability to carry out NHEJ. ${ }^{[14,21,22]}$ Function of BRCA1 in DNA repair is poorly understood. It appears to regulate the activity of the RAD50-MRE11-NBS1complex which may be involved in formation of new single-strand DNA at the site of double-strand breaks (DSBs). ${ }^{[23,24]}$

\section{Structure and Function of BRCA Protein}

BRCA1 and 2 encode two distinct proteins, respectively. These function in cellular pathways involved in DNA repair, especially DSBs.

\section{BRCA1 protein}

BRCA1 is a $220 \mathrm{kDa}$ protein composed of 1863 amino acids. It has an N-terminal RING domain useful in various protein-protein interactions. ${ }^{[25]}$ It interacts with BRCA1-associated RING domain protein 1 (BARD1), leading to increased ubiquitin ligase activity. The C-terminus of BRCA1 contains two BRCT (BRCA1 C Terminal) domains, each composed of 95 amino acid sequences. ${ }^{[26]}$ It has four beta-sheets and three alpha-helices. ${ }^{[27,28]}$ The BRCT domain is the site for phosphorylation of various DNA repair proteins. Region of the protein between exon 11 and 13 binds various proteins involved in different cellular pathways, such as retinoblastoma, c-Myc, RAD50, RAD51, and PALB2. ${ }^{[29]}$ The mutations in this region of the protein result in altered three dimensional structure resulting in misfolding or destabilization. This may prevent appropriate localization of the protein as well as faulty dimerization resulting in loss of its function. ${ }^{[28]}$

\section{BRCA2 protein}

BRCA2 is a $385 \mathrm{kDA}$ protein is composed of 3418 amino acids. It has $\mathrm{N}$-terminus transactivation domain, a long exon 11 binding specifically to RAD51 and a C-terminus binding DNA. ${ }^{[30]}$ It consists of eight BRC repeats (30-40 amino acid motifs each) encoded by exon 11. It is unique to various mammalian species and appears to perform the essential function of HR for double-stranded DNA breaks. ${ }^{[31,32]}$ BRCA1 and 2 interact with each other through PALB2. The complex associates with RAD51 for HR. ${ }^{[33]}$

\section{Subcellular dynamics of BRCA proteins}

BRCA1 and 2 proteins have similarities in subcellular localization and patterns of expression. Usually, their levels are highest in $\mathrm{S}$ phase. They have clusters at subnuclear levels which get redistributed in response to DNA damage. In meiotic cells, both proteins are found to colocalize to the synaptonemal complexes. ${ }^{[34-38]}$

BRCA2 appears to have high stoichiometry with RAD51 and is demonstrable in yeast two-hybrid system and in vitro studies with recombinant protein fragments. ${ }^{[39]}$ It also appears to carry out intracellular transport and control function of RAD51 which is an important enzyme in DNA repair pathway. ${ }^{[40]} \mathrm{A}$ similar interaction between BRCA1 protein and RAD 51 is less understood and at best can be of low stoichiometry and indirect involving multiple other proteins yet unknown. ${ }^{[41]}$

\section{Various BRCA mutations}

BRCA mutations are very diverse. Majority have no known functional significance. Certain mutations exhibit strong pathogenicity. We will review a few commonly found pathogenic BRCA mutations.

The classical mutation found in BRCA1 gene in the Ashkenazi Jewish and European population is the 5382insC. Such 
individuals are at higher risk of getting ovarian cancer than breast cancer. ${ }^{[42]}$ The most common mutation found in Indian and few Ashkenazi Jewish populations in BRCA1 gene is 185delAG. A peculiar mutation found in Polish community is a missense mutation at the Cys61 (C61G) of BRCA1. This has now been included as a standard test among investigational workup of breast and ovarian cancer patients in Poland..$^{[43,44]}$

6174delT mutation is classical in BRCA2 gene among the Jewish community. ${ }^{[45]}$ There are many more diverse mutations reported from various parts of the globe. ${ }^{[42]}$ There are also few cases reported having both BRCA1 and 2 mutations in the same individual. These patients develop cancers at a much earlier age and have more severe disease. ${ }^{[46,47]}$

By and large, mutations causing ovarian cancer tend to be located in the central part of both genes, while mutations related to breast cancer appear to be located at 5' and 3' ends of these genes. ${ }^{[48]}$

\section{Genetic Changes in Sporadic Tumors with BRCA Dysfunction}

Sporadic breast and ovarian cancers may have BRCA1 inactivation due to nongenomic mechanisms like promoter methylation that result in lowering of gene expression. On the contrary, loss of BRCA2 function in sporadic tumors does not occur by promoter hypermethylation. Many of such tumors show amplification of EMSY. This protein is a stabilizer of BRCA2 protein reducing the activity of the later. Hence, it acts like a downregulator of the BRCA2 function in the HR pathway. Amplification of the same causes functional inactivation of BRCA2 protein. ${ }^{[49]}$

\section{Enhanced Susceptibility of BRCA-Mutated Cells to Platins}

Platinum analogues such as cisplatin and carboplatin etc., have shown higher efficacy against breast and ovarian cancer cells lacking BRCA function. This is due to DNA cross-links formed by platins which remain unrepaired in BRCA-mutated cells causing "Synthetic Lethality."[50-52] TNBC cell lines show up to $83 \%$ pathologic complete response rates upon treatment with neoadjuvant cisplatin-based chemotherapy. Such high responses have been also associated with BRCA mutations or lack of BRCA expression. ${ }^{[53]}$ TNT trial showed significant OS and PFS benefit due to carboplatin in BRCA-mutated TNBC patients. ${ }^{[54,55]}$ Similar results have been seen in ovarian cancer patients with BRCA mutations. They have shown higher responses to platinum drugs with a better survival (91 vs. 54 months) and longer disease-free interval (49 vs. 19 months) as compared to BRCA wild type cancers. ${ }^{[56,57]}$

\section{Therapeutic Impact of BRCA Mutations}

BRCA mutational status has been shown to have a significant influence on the decision-making in management of these patients and their affected relatives.
Breast conservative surgery and radiotherapy data have shown that local recurrence rates in BRCA-mutated and wild-type patients are similar. ${ }^{[58-61]}$ Risk-reducing salpingo-oophorectomy (RRSO) after diagnosis of breast cancer in BRCA-mutated patients has been shown to reduce subsequent breast cancer recurrence and related mortality by $50 \%-70 \%$. This effect is more pronounced for ER-negative breast cancer than ER-positive patients. RRSO also has shown to reduce risk of ovarian cancer by $90 \%{ }^{[62]}$

Cells with defective DNA repair pathways rely on mechanisms for single-stranded DNA repair prominently through poly (ADP-ribose) polymerase-1 (PARP-1). So if PARP-1 is also inhibited, cell cannot repair any DNA lesions, and this produces a condition called 'Synthetic Lethality' in which cell undergoes apoptosis due to accumulating DNA lesions. ${ }^{[63]}$ This phenomenon has been therapeutically exploited and such PARP inhibitors have shown significant and sustained reduction in proliferation and survival of BRCA mutated cancer cells and xenografts. ${ }^{[64,65]}$ PARP inhibitors have shown good response rates among BRCA-mutated breast and ovarian cancer patients. ${ }^{[6]}$

\section{BRCAness and Scoring Systems}

With better understanding of BRCA gene functions, its mutations and their impact on DNA repair mechanisms resulting in malignancies with peculiar phenotype; researchers are trying to assess a broader entity of deficiency of HR. Various histopathology based assays are being developed and tested to understand the level of HR deficiency regardless of specific genes responsible for it. This, so-called BRCAness, can be imparted due to epigenetic silencing or germline mutations in various genes involved in HR. ${ }^{[52]}$ Such a deficit can potentially be exploited therapeutically with advent of specific inhibitors of various enzymes involved in DNA repair, such as PARP inhibitors, which would induce 'Synthetic Lethality' in such tumors. ${ }^{[13,67,68]}$

Most widely studied scoring systems for assessing HR deficiency are; HR defect (HRD) large-scale transition, HRD-loss-of-heterozygosity, and HRD-telomeric allelic imbalance. ${ }^{[69-71]}$ Various studies have shown them to be able to predict response to platinum therapy in metastatic TNBC patients. ${ }^{[72]}$ Studies are underway to predict their utility in the neoadjuvant setting also. ${ }^{[71,73]}$

A more direct approach to understand the possibility of BRCA1/2 mutations in the tumor (somatic or germ line) depending on six different molecular signatures, called HRDetect, is being evaluated to predict BRCA dysfunction (direct/indirect). Preliminary analysis has shown it to be highly sensitive (up to 99\%) to identify functionally BRCA-deficient tumors. ${ }^{[74]}$

\section{Future Perspectives}

With increasing knowledge of BRCA function, its associated pathways and potential therapeutic implications 
in these patients; there are many questions which need to be answered about these pathways. There needs to be accurate population-wise assessment of the prevalence of these dysfunctions in various communities. Furthermore, role of germ line or somatic BRCA dysfunction in other malignancies such as prostate cancers and gastrointestinal cancers needs to be probed. Therapeutic exploitation of the concept of synthetic lethality needs to be taken to a next level beyond PARP inhibition. We need to explore the feasibility of BRCA protein inhibition; which if comes true can pave the way to greater utilization of this phenomenon into all solid organ malignancies as an adjunct for platinum-based chemotherapy even in BRCA wild-type cases. More defined interdisciplinary approach toward exploring these mutations involving clinicians, basic scientists, experts from proteomics, etc., needs to be developed in future.

\section{References}

1. Nathanson KL, Wooster R, Weber BL. Breast cancer genetics: What we know and what we need. Nat Med 2001;7:552-6.

2. Walsh T, Casadei S, Lee MK, Pennil CC, Nord AS, Thornton AM, et al. Mutations in 12 genes for inherited ovarian, fallopian tube, and peritoneal carcinoma identified by massively parallel sequencing. Proc Natl Acad Sci U S A 2011;108:18032-7.

3. Antoniou A, Pharoah PD, Narod S, Risch HA, Eyfjord JE, Hopper JL, et al. Average risks of breast and ovarian cancer associated with BRCA1 or BRCA2 mutations detected in case series unselected for family history: A combined analysis of 22 studies. Am J Hum Genet 2003;72:1117-30.

4. Chen S, Parmigiani G. Meta-analysis of BRCA1 and BRCA2 penetrance. J Clin Oncol 2007;25:1329-33.

5. Rahman N, Stratton MR. The genetics of breast cancer susceptibility. Annu Rev Genet 1998;32:95-121.

6. Mavaddat N, Barrowdale D, Andrulis IL, Domchek SM, Eccles D, Nevanlinna $\mathrm{H}$, et al. Pathology of breast and ovarian cancers among BRCA1 and BRCA2 mutation carriers: Results from the consortium of investigators of modifiers of BRCA1/2 (CIMBA). Cancer Epidemiol Biomarkers Prev 2012;21:134-47.

7. Nielsen TO, Hsu FD, Jensen K, Cheang M, Karaca G, Hu Z, et al. Immunohistochemical and clinical characterization of the basal-like subtype of invasive breast carcinoma. Clin Cancer Res 2004;10:5367-74.

8. Emborgo T, Muse KI, Bednar E, Oakley HD, Litton JK, $\mathrm{Lu} \mathrm{KH}$, et al. Universal BRCA testing and family outreach for women with triple negative breast cancer. Cancer Res 2016;76 Suppl 4:AbstrP2-09-08.

9. Nik-Zainal S, Davies H, Staaf J, Ramakrishna M, Glodzik D, Zou X, et al. Landscape of somatic mutations in 560 breast cancer whole-genome sequences. Nature 2016;534:47-54.

10. Winter C, Nilsson MP, Olsson E, George AM, Chen Y, Kvist A, et al. Targeted sequencing of BRCA1 and BRCA2 across a large unselected breast cancer cohort suggests that one-third of mutations are somatic. Ann Oncol 2016;27:1532-8.

11. Hennessy BT, Timms KM, Carey MS, Gutin A, Meyer LA, Flake DD $2^{\text {nd }}$, et al. Somatic mutations in BRCA1 and BRCA2 could expand the number of patients that benefit from poly (ADP ribose) polymerase inhibitors in ovarian cancer. J Clin Oncol 2010;28:3570-6.

12. Moschetta M, George A, Kaye SB, Banerjee S. BRCA somatic mutations and epigenetic BRCA modifications in serous ovarian cancer. Ann Oncol 2016;27:1449-55.

13. Mateo J, Carreira S, Sandhu S, Miranda S, Mossop H, Perez-Lopez R, et al. DNA-repair defects and olaparib in metastatic prostate cancer. N Engl J Med 2015;373:1697-708.

14. Patel KJ, Yu VP, Lee H, Corcoran A, Thistlethwaite FC, Evans MJ, et al. Involvement of brca2 in DNA repair. Mol Cell 1998;1:347-57.

15. $\mathrm{Xu} \mathrm{X,} \mathrm{Weaver} \mathrm{Z,} \mathrm{Linke} \mathrm{SP,} \mathrm{Li} \mathrm{C,} \mathrm{Gotay} \mathrm{J,} \mathrm{Wang} \mathrm{XW,} \mathrm{et} \mathrm{al.}$ Centrosome amplification and a defective G2-M cell cycle checkpoint induce genetic instability in BRCA1 exon 11 isoform-deficient cells. Mol Cell 1999;3:389-95.

16. Sharan SK, Morimatsu M, Albrecht U, Lim DS, Regel E, Dinh C, et al. Embryonic lethality and radiation hypersensitivity mediated by rad51 in mice lacking brca2. Nature 1997;386:804-10.

17. Connor F, Bertwistle D, Mee PJ, Ross GM, Swift S, Grigorieva E, et al. Tumorigenesis and a DNA repair defect in mice with a truncating brca2 mutation. Nat Genet 1997;17:423-30.

18. Cortez D, Wang Y, Qin J, Elledge SJ. Requirement of ATM-dependent phosphorylation of brcal in the DNA damage response to double-strand breaks. Science 1999;286:1162-6.

19. Gatei M, Zhou BB, Hobson K, Scott S, Young D, Khanna KK, et al. Ataxia telangiectasia mutated (ATM) kinase and ATM and rad3 related kinase mediate phosphorylation of brcal at distinct and overlapping sites. In vivo assessment using phospho-specific antibodies. J Biol Chem 2001;276:17276-80.

20. Lee JS, Collins KM, Brown AL, Lee CH, Chung JH. HCds1-mediated phosphorylation of BRCA1 regulates the DNA damage response. Nature 2000;404:201-4.

21. Yu VP, Koehler M, Steinlein C, Schmid M, Hanakahi LA, van Gool AJ, et al. Gross chromosomal rearrangements and genetic exchange between nonhomologous chromosomes following BRCA2 inactivation. Genes Dev 2000;14:1400-6.

22. Moynahan ME, Pierce AJ, Jasin M. BRCA2 is required for homology-directed repair of chromosomal breaks. Mol Cell 2001;7:263-72.

23. Haber JE. The many interfaces of mre11. Cell 1998;95:583-6.

24. Paull TT, Cortez D, Bowers B, Elledge SJ, Gellert M. Direct DNA binding by brcal. Proc Natl Acad Sci U S A 2001;98:6086-91.

25. Wu LC, Wang ZW, Tsan JT, Spillman MA, Phung A, Xu XL, et al. Identification of a RING protein that can interact in vivo with the BRCA1 gene product. Nat Genet 1996;14:430-40.

26. Koonin EV, Altschul SF, Bork P. BRCA1 protein products. Functional motifs. Nat Genet 1996;13:266-8.

27. Huyton T, Bates PA, Zhang X, Sternberg MJ, Freemont PS. The BRCA1 C-terminal domain: Structure and function. Mutat Res 2000;460:319-32.

28. Zhang X, Moréra S, Bates PA, Whitehead PC, Coffer AI, Hainbucher K, et al. Structure of an XRCC1 BRCT domain: A new protein-protein interaction module. EMBO J 1998;17:6404-11.

29. Clark SL, Rodriguez AM, Snyder RR, Hankins GD, Boehning D. Structure-function of the tumor suppressor BRCA1. Comput Struct Biotechnol J 2012;1. pii: e201204005.

30. Chen JJ, Silver D, Cantor S, Livingston DM, Scully R. BRCA1, BRCA2, and rad51 operate in a common DNA damage response pathway. Cancer Res 1999;59:1752s-6.

31. Bignell G, Micklem G, Stratton MR, Ashworth A, Wooster R. The $\mathrm{BRC}$ repeats are conserved in mammalian BRCA2 proteins. Hum Mol Genet 1997;6:53-8.

32. Bork P, Blomberg $\mathrm{N}$, Nilges $\mathrm{M}$. Internal repeats in the BRCA2 protein sequence. Nat Genet 1996;13:22-3.

33. Zhang F, Fan Q, Ren K, Andreassen PR. PALB2 functionally 
connects the breast cancer susceptibility proteins BRCA1 and BRCA2. Mol Cancer Res 2009;7:1110-8.

34. Bertwistle D, Swift S, Marston NJ, Jackson LE, Crossland S. Functions of BRCA1 and BRCA2 in the biological response to DNA damage. J Cell Sci 2001;114(Pt 20):3591-8.

35. Blackshear PE, Goldsworthy SM, Foley JF, McAllister KA, Bennett LM, Collins NK, et al. Brca1 and brca2 expression patterns in mitotic and meiotic cells of mice. Oncogene 1998;16:61-8.

36. Connor F, Smith A, Wooster R, Stratton M, Dixon A, Campbell E, et al. Cloning, chromosomal mapping and expression pattern of the mouse brca2 gene. Hum Mol Genet 1997;6:291-300.

37. Rajan JV, Wang M, Marquis ST, Chodosh LA. Brca2 is coordinately regulated with brcal during proliferation and differentiation in mammary epithelial cells. Proc Natl Acad Sci U S A 1996;93:13078-83.

38. Chen J, Silver DP, Walpita D, Cantor SB, Gazdar AF, Tomlinson G, et al. Stable interaction between the products of the BRCA1 and BRCA2 tumor suppressor genes in mitotic and meiotic cells. Mol Cell 1998;2:317-28.

39. Chen PL, Chen CF, Chen Y, Xiao J, Sharp ZD, Lee WH, et al. The BRC repeats in BRCA2 are critical for RAD51 binding and resistance to methyl methanesulfonate treatment. Proc Natl Acad Sci U S A 1998;95:5287-92.

40. Davies AA, Masson JY, Mcllwraith MJ, Stasiak AZ, Stasiak A, Venkitaraman AR, et al. Role of BRCA2 in control of the RAD51 recombination and DNA repair protein. Mol Cell 2001;7:273-82.

41. Scully R, Chen J, Plug A, Xiao Y, Weaver D, Feunteun J, et al. Association of BRCA1 with rad51 in mitotic and meiotic cells. Cell 1997;88:265-75.

42. Karami F, Mehdipour P. A comprehensive focus on global spectrum of BRCA1 and BRCA2 mutations in breast cancer. Biomed Res Int 2013;2013:928562.

43. Menkiszak J, Chudecka-Głaz A, Gronwald J, Bedner R, Cymbaluk-Płoska A, Wezowska M, et al. Characteristics of selected clinical features in BRCA1 mutation carriers affected with breast cancer undergoing preventive female genital tract surgeries. Ginekol Pol 2013;84:758-64.

44. Szwiec M, Jakubowska A, Górski B, Huzarski T, Tomiczek-Szwiec J, Gronwald $\mathrm{J}$, et al. Recurrent mutations of BRCA1 and BRCA2 in poland: An update. Clin Genet 2015;87:288-92

45. Struewing JP, Hartge P, Wacholder S, Baker SM, Berlin M, McAdams $\mathrm{M}$, et al. The risk of cancer associated with specific mutations of BRCA1 and BRCA2 among Ashkenazi Jews. N Engl J Med 1997;336:1401-8.

46. Heidemann S, Fischer C, Engel C, Fischer B, Harder L, Schlegelberger B, et al. Double heterozygosity for mutations in BRCA1 and BRCA2 in German breast cancer patients: Implications on test strategies and clinical management. Breast Cancer Res Treat 2012;134:1229-39.

47. Lavie O, Narod S, Lejbkowicz F, Dishon S, Goldberg Y, Gemer O, et al. Double heterozygosity in the BRCA1 and BRCA2 genes in the Jewish population. Ann Oncol 2011;22:964-6.

48. Rebbeck TR, Mitra N, Wan F, Sinilnikova OM, Healey S, McGuffog L, et al. Association of type and location of BRCA1 and BRCA2 mutations with risk of breast and ovarian cancer. JAMA 2015;313:1347-61.

49. Muggia F, Safra T. 'BRCAness' and its implications for platinum action in gynecologic cancer. Anticancer Res 2014;34:551-6.

50. Alsop K, Fereday S, Meldrum C, deFazio A, Emmanuel C, George $\mathrm{J}$, et al. BRCA mutation frequency and patterns of treatment response in BRCA mutation-positive women with ovarian cancer: A report from the Autralian ovarian cancer study group. J Clin Oncol 2012;30:2654-63.

51. Gorodnova TV, Sokolenko AP, Ivantsov AO, Iyevleva AG, Suspitsin EN, Aleksakhina SN, et al. High response rates to neoadjuvant platinum-based therapy in ovarian cancer patients carrying germ-line BRCA mutation. Cancer Lett 2015;369:363-7.

52. Lord CJ, Ashworth A. BRCAness revisited. Nat Rev Cancer 2016;16:110-20.

53. Silver DP, Richardson AL, Eklund AC, Wang ZC, Szallasi Z, Li Q, et al. Efficacy of neoadjuvant cisplatin in triple-negative breast cancer. J Clin Oncol 2010;28:1145-53.

54. Kilburn LS, TNT Trial Management Group. 'Triple negative' breast cancer: A new area for phase III breast cancer clinical trials. Clin Oncol (R Coll Radiol) 2008;20:35-9.

55. Tutt A, Ellis P, Kilburn LS, Gilett C, Pinder S, Abraham J, et al. The TNT trial: A randomized phase III trial of carboplatin (C) compared with docetaxel (D) for patients with metastatic or recurrent locally advanced triple negative or BRCA1/2 breast cancer (CRUK/07/012). Abstract S3-01 Presented at the San Antonio Breast Cancer Symposium, San Antonio, TX; 2014. P. 9-13.

56. Cass I, Baldwin RL, Varkey T, Moslehi R, Narod SA, Karlan BY, et al. Improved survival in women with BRCA-associated ovarian carcinoma. Cancer 2003;97:2187-95.

57. Tan DS, Rothermundt C, Thomas K, Bancroft E, Eeles R, Shanley S, et al. "BRC Aness" syndrome in ovarian cancer: A case-control study describing the clinical features and outcome of patients with epithelial ovarian cancer associated with BRCA1 and BRCA2 mutations. J Clin Oncol 2008;26:5530-6.

58. Brekelmans CT, Tilanus-Linthorst MM, Seynaeve C, vd Ouweland A, Menke-Pluymers MB, Bartels CC, et al. Tumour characteristics, survival and prognostic factors of hereditary breast cancer from BRCA2-, BRCA1- and non-BRCA1/2 families as compared to sporadic breast cancer cases. Eur J Cancer 2007;43:867-76.

59. Pierce LJ, Levin AM, Rebbeck TR, Ben-David MA, Friedman E, Solin LJ, et al. Ten-year multi-institutional results of breast-conserving surgery and radiotherapy in BRCA1/2-associated stage I/II breast cancer. J Clin Oncol 2006;24:2437-43.

60. Robson M, Svahn T, McCormick B, Borgen P, Hudis CA, Norton L, et al. Appropriateness of breast-conserving treatment of breast carcinoma in women with germline mutations in BRCA1 or BRCA2: A clinic-based series. Cancer 2005;103:44-51.

61. Pierce LJ, Phillips KA, Griffith KA, Buys S, Gaffney DK, Moran MS, et al. Local therapy in BRCA1 and BRCA2 mutation carriers with operable breast cancer: Comparison of breast conservation and mastectomy. Breast Cancer Res Treat 2010;121:389-98.

62. Metcalfe K, Lynch HT, Foulkes WD, Tung N, Kim-Sing C, Olopade OI, et al. Effect of oophorectomy on survival after breast cancer in BRCA1 and BRCA2 mutation carriers. JAMA Oncol 2015;1:306-13.

63. Ashworth A. A synthetic lethal therapeutic approach: Poly (ADP) ribose polymerase inhibitors for the treatment of cancers deficient in DNA double-strand break repair. J Clin Oncol 2008;26:3785-90.

64. Bryant HE, Schultz N, Thomas HD, Parker KM, Flower D, Lopez E, et al. Specific killing of BRCA2-deficient tumours with inhibitors of poly (ADP-ribose) polymerase. Nature 2005;434:913-7.

65. Farmer H, McCabe N, Lord CJ, Tutt AN, Johnson DA, Richardson TB, et al. Targeting the DNA repair defect in BRCA mutant cells as a therapeutic strategy. Nature 2005;434:917-21. 
66. Robson M, Im SA, Senkus E, Xu B, Domchek SM, Masuda N, et al. Olaparib for metastatic breast cancer in patients with a germline BRCA mutation. N Engl J Med 2017;377:523-33.

67. McCabe N, Turner NC, Lord CJ, Kluzek K, Bialkowska A, Swift $\mathrm{S}$, et al. Deficiency in the repair of DNA damage by homologous recombination and sensitivity to poly (ADP-ribose) polymerase inhibition. Cancer Res 2006;66:8109-15.

68. McGrail DJ, Lin CC, Garnett J, Liu Q, Mo W, Dai H, et al. Improved prediction of PARP inhibitor response and identification of synergizing agents through use of a novel gene expression signature generation algorithm. NPJ Syst Biol Appl 2017;3:8.

69. Popova T, Manié E, Rieunier G, Caux-Moncoutier V, Tirapo C, Dubois $\mathrm{T}$, et al. Ploidy and large-scale genomic instability consistently identify basal-like breast carcinomas with BRCA1/2 inactivation. Cancer Res 2012;72:5454-62.

70. Abkevich V, Timms KM, Hennessy BT, Potter J, Carey MS, Meyer LA, et al. Patterns of genomic loss of heterozygosity predict homologous recombination repair defects in epithelial ovarian cancer. Br J Cancer 2012;107:1776-82.

71. Birkbak NJ, Wang ZC, Kim JY, Eklund AC, Li Q, Tian R, et al. Telomeric allelic imbalance indicates defective DNA repair and sensitivity to DNA-damaging agents. Cancer Discov 2012;2:366-75.

72. Isakoff SJ, Mayer EL, He L, Traina TA, Carey LA, Krag KJ, et al. TBCRC009: A Multicenter phase II clinical trial of platinum monotherapy with biomarker assessment in metastatic triple-negative breast cancer. J Clin Oncol 2015;33:1902-9.

73. Telli ML, Timms KM, Reid J, Hennessy B, Mills GB, Jensen KC, et al. Homologous recombination deficiency (HRD) score predicts response to platinum-containing neoadjuvant chemotherapy in patients with triple-negative breast cancer. Clin Cancer Res 2016;22:3764-73.

74. Davies H, Glodzik D, Morganella S, Yates LR, Staaf J, Zou X, et al. HRDetect is a predictor of BRCA1 and BRCA2 deficiency based on mutational signatures. Nat Med 2017;23:517-25. 